REVI EWS

\title{
Medical errors: Moral and ethical considerations
}

\author{
Wilfred Bonney \\ School of Business and Technology, Capella University, Minneapolis, MN, USA
}

Correspondence: Wilfred Bonney, Ph.D. Address: School of Business and Technology, Capella University, Minneapolis, MN, USA. E-mail: wbonney@capellauniversity.edu

Received: October 11, 2013

Dol : $10.5430 /$ jha.v3n2p80
Accepted: November 18, 2013

URL: http://dx.doi.org/10.5430/jha.v3n2p80

\section{Abstract}

Medical errors are an inevitable part of the practice of medicine and pose a significant threat to the safety of patients. Improper management of healthcare professionals, clinical workflow processes, and information systems often leads to medical errors. Disclosure of medical errors to patients and family members serves as a catalyst for litigation and thus, the establishment of appropriate moral and ethical standards cannot be ignored when implementing solutions to remedy the situation. In this paper, a systematic literature review was used to explore and evaluate the moral and ethical issues that confront the healthcare industry as a result of medical errors. The practical implications of medical errors were also discussed.

\section{Key words}

Medical errors, Ethics, Morality, Ethical principles, Medical practice

\section{I ntroduction}

The healthcare delivery system is a marketplace in which expert care is provided to patients and information is collected, stored, and traded. Recognizing the healthcare system as a marketplace where information is traded, Maynard and Bloor ${ }^{[1]}$ noted that the market for healthcare is characterized by exchange of information and uncertainty, and thus the need for external performance management is of prime concern. Managing the exchange of information and uncertainty requires the establishment of proper performance management system to monitor and support the workflow of healthcare professionals and information processes. Improper management of healthcare professionals, clinical workflow processes, and information systems often leads to medical errors.

The healthcare delivery system is vulnerable to medical errors because of its decentralized and fragmented nature ${ }^{[2-4]}$. System and process failures contribute to medical errors in medical practice ${ }^{[5]}$. According to Maynard and Bloor ${ }^{[1]}$, consumers of the healthcare delivery system are ill-placed to judge how much satisfaction is likely to be derived from a medical intervention. Hence, when unsatisfactory outcomes such as medical errors and malpractices occur, they are often met with grave consequences. For example, Institute of Medicine (IOM) ${ }^{[3]}$ noted that healthcare professionals pay exceedingly with loss of moral and frustration at not being able to provide the best care possible for their consumers.

In the healthcare industry, medical errors embody a serious public health dilemma and pose a significant threat to the safety of patients ${ }^{[2]}$. The IOM ${ }^{[3]}$ report entitled “To Err is Human: Building a Safer Health System”, alleged that between 
45,000-98,000 Americans die each year as a result of medical errors. This report has generated larger debates in the medical community as to how best to decrease medical errors and increase patient safety in medical practice ${ }^{[5-11]}$.

Medical errors are an inevitable part of the practice of medicine and do occur in approximately $2 \%$ of all hospitalizations ${ }^{[12]}$. Disclosure of medical errors to patients and family members serves as a catalyst for litigation ${ }^{[13]}$ and thus the establishment of appropriate moral and ethical standards cannot be ignored when implementing solutions to remedy the situation. Rathert and Phillips ${ }^{[14]}$ emphasized on the importance of managing ethical environment in healthcare organizations. According to Rathert and Phillips ${ }^{[14]}$, proactive management of organizational ethics in healthcare organizations is imperative.

The objective of this paper is to explore and evaluate the moral and ethical issues that confront the healthcare industry as a result of medical errors. The first part gives an overview of medical errors. In the second part, the focus is on the moral and ethical issues that confront the healthcare industry as a result of medical errors. The third part discusses the practical implications of medical errors.

\section{Method}

A systematic literature review, based on research articles from 1999 to 2012, was used to explore and evaluate the moral and ethical issues that confront the healthcare industry as a result of medical errors. The methodology involved a systematic review of relevant publications, found and accessed with the help of ProQuest (with multiple databases option) and EBSCOhost databases. Additional sources were retrieved using the MeSH Browser, SAGE Journals Online, ScienceDirect, Google Scholar, and ACM digital libraries. The targeted search terms consisted of the combination of keywords and/or phrases including: (a) medical errors; (b) medical errors AND ethics; (c) medical errors AND ethics AND/OR moral; (d) medical errors AND ethical principles and (e) ethical principles.
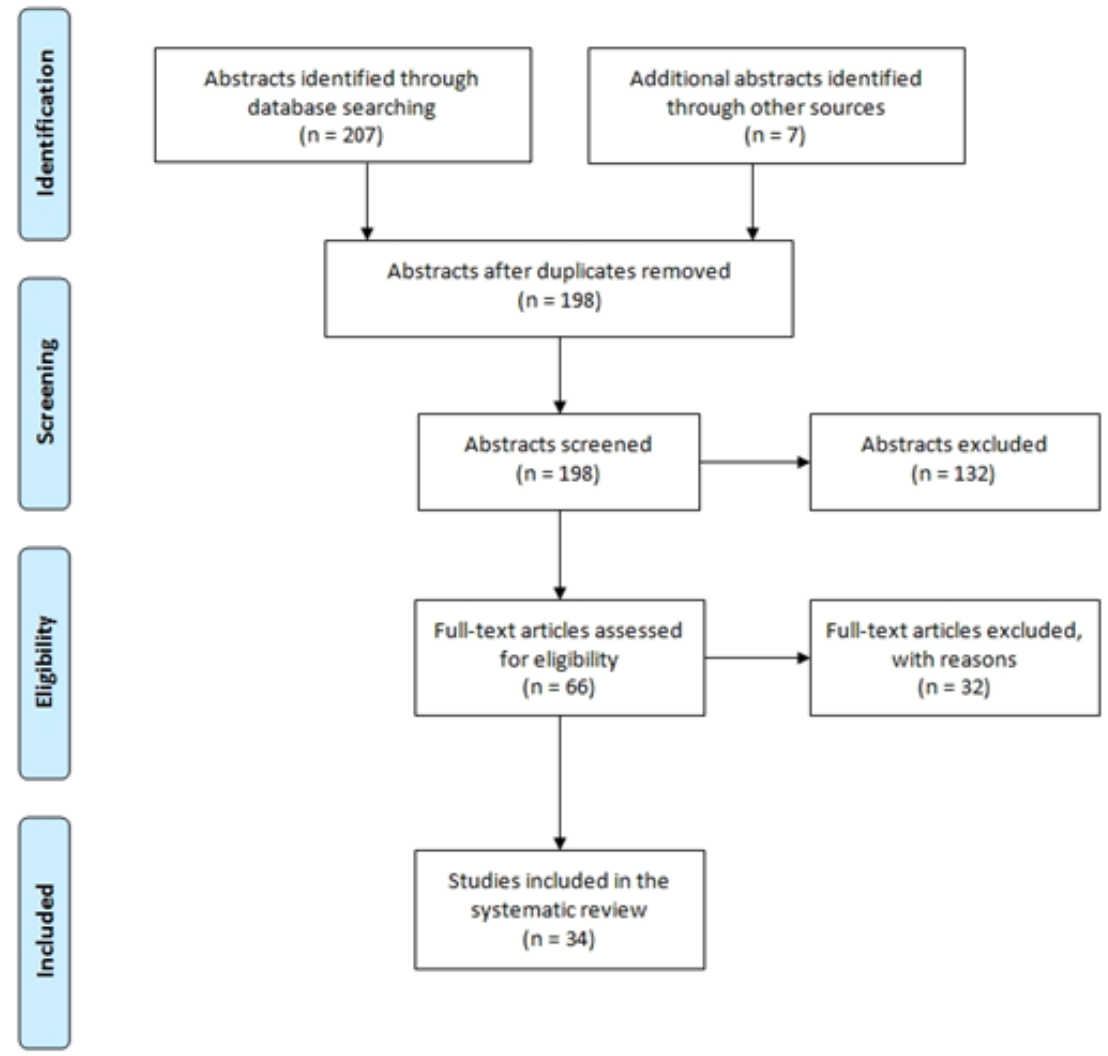

Figure. The PRISMA flow diagram for the systematic review 
Overall, 198 articles were identified and 34 of them were reviewed in full. Findings from the reviewed papers are synthesized, paraphrased (in some cases quoted) and categorized under four broad themes: Overview of Medical Errors; Moral and Ethical Issues; Practical Implications; and Conclusion. Studies were included in the analysis if they reported on moral and ethical issues that confront the healthcare industry as a result of medical errors. The inclusion criteria also required that the selected full-text articles were (a) published in English language; (b) published in the date range between 1999 and 2012; and (c) electronically available in full-text. All identified studies that did not meet the requirements for the inclusion criteria were excluded from the systematic review. The PRISMA (Preferred Reporting Items for Systematic reviews and Meta-Analysis) flow diagram ${ }^{[15]}$ for the systematic review is shown in the Figure.

\section{Results}

\subsection{Overview of medical errors}

The definition of medical errors is vague, inadequate, and generic; and often makes the interpretation of medical errors open to larger debate in the medical community and the general public ${ }^{[2,10,16]}$. According to the MeSH Browser ${ }^{[17]}$, medical errors are errors or mistakes committed by healthcare professionals which result in harm to patients. IOM ${ }^{[3]}$ defined medical error as the "failure of a planned action to be completed as intended or the use of a wrong plan to achieve an aim”. Medical errors differ from malpractice, which in itself involves the negligence of the healthcare professional to provide adequate and appropriate services to the patient through reprehensible ignorance or criminal intent ${ }^{[17]}$.

The causes of medical errors are numerous and have many components ${ }^{[2,3,18-20]}$. Acknowledging the fact that medical errors are not typically caused by the negligent and/or incompetent healthcare professionals, Crane and Crane ${ }^{[19]}$ noted that "medical errors are a direct result of how the health system is organized and how care is delivered". Crane and Crane ${ }^{[19]}$ attributed the cause of medical errors to the fragmented nature of outdated article-based system that are highly variable and error prone; and patient's medical information that are scattered across numerous medical records and kept by different healthcare providers in different locations. Moreover, the illegible handwritten medical orders and prescriptions from clinicians were attributed to the cause of medical errors ${ }^{[19]}$.

Medical errors come in several forms. Pollack et al. ${ }^{[20]}$ categorized medical errors into two forms: systems errors and individuals errors. Whereas systems errors focus on errors originating from the use of healthcare information systems, individuals errors originate from practicing healthcare professionals ${ }^{[2,20]}$. Reason ${ }^{[21]}$ referred to these two types of errors as person approach and system approach. While the person approach focuses on the errors of individuals (i.e., Clinicians, Nurses, Pharmacists, etc.), the system approach focuses primarily on the conditions under which individuals work ${ }^{[21]}$. Understanding the origin of each types of error does not guarantee faster resolution in an event of medical error, but rather provide the necessary understanding on how to resolve and prevent further errors ${ }^{[20]}$.

In the context of systems errors, Coiera et al. ${ }^{[18]}$ attributed the possibility of medical errors emanating from the continuing use of Clinical Decision Support Systems (CDSS) in medical practice. According to Coiera et al. ${ }^{[18]}$, the use of CDSS can "improve the overall safety and quality of health care delivery, but may also introduce machine-related errors". Coiera et $a l .{ }^{[18]}$ noted that automation biases and using evidence-based retrieval systems may generate decision errors. For example, Coiera et al. ${ }^{[18]}$ asserted that the use of poor quality health data in the development of CDSS could lead to wrong medications and misdiagnosis.

One of the basic tenets of human errors is that everyone commits errors ${ }^{[22]}$. Nolan ${ }^{[11]}$ found that many errors are attributable to the characteristics of human cognition. Reason ${ }^{[21]}$ made similar assertion by acknowledging that the person approach "has serious shortcomings and is ill suited to the medical domain". Unanticipated medical errors could results from systemic factors like distractions, poor communication systems, poorly designed equipment, as well as human 
factors such as memory lapse, fatigue, carelessness, negligence, recklessness and cognitive bias when making critical decisions ${ }^{[21,22]}$. These factors contribute to the inevitability of medical errors in clinical practice.

Healthcare providers can prevent the incidence of medical errors by identifying their causes, devising solutions, and measuring the success of improvement ${ }^{[2]}$. While medical errors affect the lives of many patients each year, findings from the literature suggest that most medical errors are preventable ${ }^{[9,19]}$. Preventative measures will involve adequate leadership, attention, and resources ${ }^{[3]}$. Examples of medical errors include adverse drug events and improper transfusions; surgical injuries and wrong-site surgery; suicides, restraint-related injuries or death; pressure ulcers; and mistaken patient identities ${ }^{[3]}$.

Promoting patient safety in healthcare delivery will require that systemic error management techniques are in place to mitigate and contain the damaging effects of unanticipated medical errors. Many researchers have proposed error management techniques and strategies for managing medical errors. As a case in point, Reason ${ }^{[21]}$ proposed error management techniques that involved limiting the incidence of dangerous errors and creating systems that are better equipped to tolerate and contain the damaging effects of the errors. In another study, Nolan ${ }^{[11]}$ proposed three strategies that included: (a) designing systems to prevent medical errors; (b) designing systems to make medical errors visible; and (c) designing procedures for mitigating unanticipated medical errors. Nolan ${ }^{[11]}$ also recommended that the error prevention strategies are supplemented with tactics that involves reducing complexity, optimizing information processing, automating wisely, using constraints, and mitigating the unwanted side effects of change.

\subsection{Moral and ethical issues}

Several moral and ethical issues confront the healthcare industry as a result of medical errors. In his attempt to distinguish between morality and ethics, Sullivan ${ }^{[23]}$ noted that while morality refers to social conventions about right and wrong, ethics refers to the theoretical and systematic understanding of the moral life. Moral reasoning informs every choice of actions made in medical practice ${ }^{[23]}$. The moral and ethical issues that confront the healthcare industry as a result of medical errors could be categorized into the following five concepts: Autonomy and Right to Self-Determination; Beneficence and Nonmaleficence; Disclosure and Right to Knowledge; Justice; and Veracity ${ }^{[14,23,24]}$. The following sections describe the essence of these five concepts in the healthcare industry.

\subsubsection{Autonomy and right to self-determination}

Autonomy and right to self-determination acknowledges the patients' right to make choices, to hold views, and to take actions based on personal values and beliefs ${ }^{[8,24]}$. The autonomy principle (i.e., respect for persons) is often associated with different concepts such as privacy, voluntariness, self-mastery, choosing one's own moral position, and accepting responsibility of one's own choice ${ }^{[24]}$. This ethical principle requires that healthcare providers follow moral rules that include (a) respecting the privacy of patients, (b) protecting the integrity and confidentiality of personalized health information, (c) obtaining informed consent for interventions with patients, (d) helping patients make important decisions concerning interventions, and (e) respecting patients' decisions about their medical care, even if the patients are refusing care $^{[8]}$.

Patients have the right to be informed about medical errors. Drawing upon the work of Beauchamp and Childress ${ }^{\text {[25], }}$ Henry ${ }^{[8]}$ noted that healthcare professionals are ethically "obligated to disclose information, to ensure understanding, and to allow for adequate decision making”. Kalra, Massey, and Mulla ${ }^{[26]}$ made similar assessment by noting that patients have the right to be informed about medical errors in terms of the respect owned to them by physicians and other healthcare providers. Physicians can demonstrate respect for their patients' autonomy and right to self-determination by obtaining the patient's valid consent for every medical intervention ${ }^{[23]}$. The informed consent serves as an authoritative document indicating that the patient understands the risks and benefits of a procedure. Moreover, the acquisition of the informed consent, from patients, also protects physicians against litigation if an unanticipated medical error is listed as part of the risks (e.g., complications of surgery). 


\subsubsection{Beneficence and nonmaleficence}

The beneficence ethical principle emphasizes the need to promote good and do what is best for the patient ${ }^{[24]}$. In other words, beneficence strives to promote benefits to patients by maximizing treatment outcomes while minimizing risks. The ethical principle of nonmaleficence, on the other hand, dictates the need not to inflict harm on patients intentionally or carelessly ${ }^{[23]}$. Nonmaleficence reassures patients that no major harm will be inflicted upon them during medical interventions and/or treatments.

Clinicians often find themselves in a situation whereby promoting good/benefits sometimes demand the need to inflict harm to patients. For example, a patient receiving an injection for a typhoid fever treatment will experience a bodily harm through the use of a syringe. However, in this scenario, if there are no other treatment options, then the physician might proceed with the assumption that the benefit of the treatment will outweigh the bodily harm through injection. It is, therefore, the moral obligation of clinicians to maximize benefits and minimize harm while providing treatments or services to patients ${ }^{[23]}$.

Clinicians also have an ethical responsibility not to inflict harm on patients carelessly or intentionally ${ }^{[23]}$. However, unanticipated medical errors that inflict harms on patients conflict with the obligation of nonmaleficence ${ }^{[14]}$. Sullivan ${ }^{[23]}$ recognized this discrepancy by noting that the duty not to harm usually prohibits actions while the duty to promote good prescribes actions from certain people. It is therefore very important that when medical errors occur, healthcare professionals take the necessary steps in ensuring that they do not lead to harm ${ }^{[4]}$.

\subsubsection{Disclosure and right to knowledge}

Patients need disclosure and knowledge to inform decision-making and judgement. Failure to disclose information on medical errors affects the patient's ability to make intelligent decision; impairs patient-doctor trust; and causes patients to litigate ${ }^{[26]}$. Systematic disclosure of medical errors, however, creates an opportunity for patients and caregivers to become part of the capacity to improve patient-doctor trust and fidelity ${ }^{[9,13,27,28]}$. Although various findings from the literature indicate widespread support for disclosing harm-causing medical errors to patients, other research data fail to report on exactly what is being disclosed to the affected patients and/or their families ${ }^{[16]}$.

Healthcare providers and professionals have an obligation to support the disclosure of medical errors to patients for both ethical and practical reasons ${ }^{[13,29]}$. One approach to showing this support is to develop a clear and unambiguous disclosure plan. For example, Chafe, Levinson, and Sullivan ${ }^{[30]}$ indicated that the development of such a disclosure plan needs to include a "timeline with specific dates and a communication strategy for disclosure to all affected groups, including the general public". All patients who have been inflicted with harm by the medical error need to be followed up individually and a system should be in place to review the error and recommend appropriate changes ${ }^{[30,31]}$.

Disclosure of medical errors to patients is very difficult and challenging ${ }^{[13,27]}$. Most healthcare institutions are not generally disposed to handle disclosure of medical errors ${ }^{[30]}$. In the case of errors involving multiple patients, the process of resolving the issue could be resource-intensive and time consuming; and might result in accusations amongst the different healthcare providers and professionals involved ${ }^{[30]}$. Hence, the development of clear "institutional policies on disclosure of unanticipated patient care outcomes is an important step" ${ }^{[8]}$ to safeguarding and protecting medical practice from unanticipated medical errors. Kalra et al. ${ }^{[26]}$ noted that the key global policy on disclosure of a medical error is to apologize to the patients involved.

\subsubsection{J ustice}

The objective of the ethical principle of justice is to determine how the interest of one patient is balanced against the interest of another patient ${ }^{[32]}$. The justice ethical principle ensures that patients are treated equitably, and the benefits and burdens of treatments are fairly distributed and communicated ${ }^{[24]}$. Distributive justice refers to fair, equitable, and appropriate distribution of privileges, benefits, and/or services in medical practice ${ }^{[23]}$. This ethical principle requires 
healthcare professionals to be fair in the distribution of treatments to patients. More specifically, healthcare professionals have an ethical obligation to ensure that the distribution and/or allocation of scarce medical resources to patients would not lead to unanticipated medical errors.

\subsubsection{Veracity}

Within the healthcare setting, veracity is defined as a "comprehensive, accurate, and objective transmission of information alongside the practitioner's ability to foster the patient's understanding of that information" ${ }^{[8]}$. Veracity reaffirms and nurtures the fidelity and trust of the patient-doctor relationship. Clinicians are morally and ethically obligated to tell the truth about treatment outcomes and any associated benefits, risks, and unanticipated medical errors before treatment is given to patients without much hesitation ${ }^{[8,24]}$.

Healthcare professionals are ethically bound to disclose and tell the truth about harm-causing medical errors to patients ${ }^{[16]}$. Telling the truth about unanticipated medical errors nurtures trust or fidelity amongst the patient-doctor relationship. It is in this regard that Henry ${ }^{[8]}$ noted that the concept of veracity establishes understanding that there is respect for patients, fidelity, promise keeping, and truth telling with the end result being trust for both the healthcare professional and the patient.

\section{Practical implications}

The idea of safeguarding medical practice from unanticipated medical errors is very challenging and complex ${ }^{[13]}$. Several researchers have proposed the need for the development of comprehensive disclosure policy and apology law that aim at bringing the patient closer to the understanding of such a scenario ${ }^{[8,9,29,30,33]}$. Implementing these recommendations in medical practice is not a one step process. Pollack et al. ${ }^{[20]}$ recommended four steps processes towards the resolution of medical errors: (1) recognizing the impact of the error; (2) disclosing the error; (3) apologizing for the error; and (4) making amends for the error.

Apologizing for the medical errors is an important step toward resolution ${ }^{[20,28,33]}$. Robbennolt ${ }^{[28]}$ stressed on the need for physicians to respond to medical errors with an apology. However, apologies should be used with caution. Robbennolt ${ }^{[28]}$ noted that "apologies that accept responsibility are more effective than similar expressions that simply express sympathy". Robbennolt ${ }^{[28]}$ was convinced that the use of apology can help medical practice by decreasing blame, decreasing anger, increasing trust, and improving relationships.

Beyond disclosing and apologizing for medical errors, it is also equally important to make amends for the errors ${ }^{[20]}$. This could be achieved by caring for the patient's medical, financial, and emotional needs. In the case of the clinician involved, steps should be taken to ensure that the same mistake does not occur again ${ }^{[20]}$. Drawing upon the work of IOM ${ }^{[3]}$, Chaiken and Holmquest ${ }^{[5]}$ recommended the need for fundamental changes within the healthcare system to better deliver uniform and quality healthcare. $\operatorname{IOM}^{[3]}$ also recommended a four-tiered improvement strategy that includes: establishing leadership, research, tools, and protocols to enhance the knowledge base about safety; identifying and learning from errors; raising performance standards and expectations for improvements in safety; and implementing safety systems in healthcare organizations.

Although fear of litigation or legal liability is cited as one of the leading barriers to disclosure and apology by physicians and risk managers, there exist no established link between the risk of litigation and willingness to disclose medical errors ${ }^{[28]}$. Specifically, Robbennolt ${ }^{[28]}$ found that there seems to be no significant correlation between reluctance to disclose medical errors and the likelihood of litigation. This finding reinforces the need for physicians and other healthcare providers to continue the practice of disclosing and apologizing for medical errors when they do occur. While this study supports disclosure, it is not yet clear that disclosure will always reduce litigation. Nevertheless, healthcare professionals are morally and ethically obligated to disclose medical errors. 


\section{Conclusion}

This paper has discussed the moral and ethical issues that confront the healthcare industry as a result of medical errors. There is a general consensus amongst many researchers that preventing medical errors requires the establishment and management of compliance-based and values-based ethical environments ${ }^{[14]}$. Whereas the compliance-based ethical environment describes ethical policies that focuses on rules, monitoring employee behaviour, and punishing ethical misconduct; the values-based ethical environment describes ethical policies that focuses on employee's commitment to values and norms related to practices ${ }^{[14]}$. A successful implementation of these ethical environments will guide healthcare providers in managing risks, establishing rules, monitoring employees’ behaviours, and punishing ethical misconducts ${ }^{[14]}$. Punishing ethical misconduct should be based on the core ethical principles (i.e., autonomy, beneficence, nonmaleficence, justice, and veracity).

Healthcare providers and professionals require adequate resources in managing and resolving medical errors. In other words, preventing medical errors requires systematic changes in the healthcare workflow processes ${ }^{[5]}$. For example, in safeguarding patient safety in medical practice, Chaiken and Holmquest ${ }^{[5]}$ recommended that healthcare providers categorize the occurrence of medical errors, examine the associated processes, and rework the processes producing the errors.

In the context of preventative systems errors, the use of properly designed healthcare information systems such as Electronic Health Record (EHR), Electronic Medical Record (EMR), and CDSS could be very helpful ${ }^{[19,34,35]}$. These systems serve as essential toolkits for preventing medical errors by enforcing clinician adherence to evidence-based practice guidelines and facilitating clinical decision-making processes ${ }^{[36]}$. For example, in a study conducted to examine whether physicians' use of CDSS affects patient satisfaction and/or blame for medical outcomes, Pezzo and Pezzo ${ }^{\text {[36] }}$ found that the use of decision support system was very effective in reducing liability after medical errors. Grepperud ${ }^{\text {[7] }}$ also recommended the need for the development of mandatory and voluntary error reporting systems that hold healthcare providers accountable for their performance in medical practice.

Ongoing teaching of healthcare professionals and medical students about the hazards of medical errors is also essential in preventing future occurrence of medical errors. Many healthcare professionals and medical students have different perceptions and attitudes towards the handling of medical errors ${ }^{[10]}$. The medical education should enhance awareness and facilitate medical students' critical analysis of medical errors ${ }^{[37]}$. Paxton and Rubinfeld ${ }^{[37]}$ found brief educational intervention into medical curriculum to be statistically significant in improving the understanding of medical errors amongst medical students as well as enhancing medical students' awareness and proactive handling of medical errors. The teaching should also embrace best practices of disclosing medical errors to the patients and their family members.

Above all, it is important that healthcare providers create a cultural environment in which healthcare professionals will feel free to report, disclose, and discuss medical errors ${ }^{[6,8,20]}$. Physicians should not be coerced to disclose medical errors to patients. Coercing healthcare providers and professionals to disclose medical errors will eliminate trust and fidelity amongst the patient-doctor relationship. It is therefore imperative that future research focus on developing a comprehensive ethical framework that recognizes the autonomy and self-determination of patients as they move through the continuum of the healthcare delivery system.

\section{References}

[1] Maynard A, Bloor K. Trust and performance management in the medical marketplace. J R Soc Med. 2003; 96(11): 532-539. http://dx.doi.org/10.1258/jrsm.96.11.532

[2] Grober E, Bohnen J. Defining medical error. Can J Surg. 2005; 48(1): 39-44. PMid: 15757035. 
[3] Institute of Medicine (IOM). To err is human: Building a safer health system [Internet]. 1999 [cited 2012 Apr 21]. Available from: http://www.iom.edu/ /media/Files/Report\%20Files/1999/To-Err-is-Human/To\%20Err\%20is\%20Human\%201999\%20\%20report \%20brief.pdf

[4] Taib IA, McIntosh AS, Caponecchia C, Baysari MT. A review of medical error taxonomies: A human factors perspective. Saf Sci. 2011; 49(5): 607-615. http://dx.doi.org/10.1016/j.ssci.2010.12.014

[5] Chaiken BP, Holmquest DL. Patient safety: Modifying processes to eliminate medical errors. Nurs Outlook. 2003; 51(3): 21-24. http://dx.doi.org/10.1016/S0029-6554(03)00097-6

[6] Cohen R. Assessing professional behaviour and medical error. Med Teach. 2001; 23(2): 145-151. http://dx.doi.org/10.1080/01421590120036556

[7] Grepperud S. Medical errors: Mandatory reporting, voluntary reporting, or both? Eur J Law Econ. 2005; 20(1): 99-112. http://dx.doi.org/10.1007/s10657-005-1019-8

[8] Henry LL. Disclosure of medical errors: Ethical considerations for the development of a facility policy and organizational culture change. Policy Polit Nurs Pract. 2005; 6(2): 127-134. http://dx.doi.org/10.1177/1527154404272611

[9] Hibbard JH, Peters E, Slovic P, Tusler M. Can patients be part of the solution? Views on their role in preventing medical errors. Med Care Res Rev. 2005; 62(5): 601-616. http://dx.doi.org/10.1177/1077558705279313

[10] Muller D, Ornstein K. Perceptions of and attitudes towards medical errors among medical trainees. Med Educ. 2007; 41(7): 645-652. PMid: 17614884. http://dx.doi.org/10.1111/j.1365-2923.2007.02784.x

[11] Nolan TW. System changes to improve patient safety. BMJ. 2000; 320(7237): 771-773. PMid: 10720364. http://dx.doi.org/10.1136/bmj.320.7237.771

[12] Martinez W, Lo B. Medical students' experiences with medical errors: An analysis of medical student essays. Med Educ. 2008; 42(7): 733-741. http://dx.doi.org/10.1111/j.1365-2923.2008.03109.x

[13] Wright J, Opperman G. The disclosure of medical errors: A catalyst for litigation or the way forward for better patient management? Clin Risk. 2008; 14(5): 193-196. http://dx.doi.org/10.1258/cr.2008.080047

[14] Rathert C, Phillips W. Medical error disclosure training: Evidence for values-based ethical environments. J Bus Ethics. 2010; 97(3): 491-503. http://dx.doi.org/10.1007/s10551-010-0520-3

[15] Moher D, Liberati A, Tetzlaff J, Altman, DG, The PRISMA Group. Preferred Reporting Items for Systematic Reviews and Meta-Analyses: The PRISMA Statement. PLoS Med. 2009; 6(6): e1000097. http://dx.doi.org/10.1371/journal.pmed1000097

[16] Banja JD. Problematic medical errors and their implications for disclosure. HEC Forum. 2008; 20(3): 201-213. http://dx.doi.org/10.1007/s10730-008-9072-7

[17] MeSH Browser. Medical errors [Internet]. 2012 [cited 2012 Jun 21]. Available from: http://www.nlm.nih.gov/cgi/mesh/2012/MB_cgi?mode=\&term=Medical+Errors\&field=entry

[18] Coiera E, Westbrook JI, Wyatt JC. The safety and quality of decision support systems. Methods Inf Med. 2006; 45(Suppl. 1): 20-25.

[19] Crane JN, Crane FG. The adoption of electronic medical record technology in order to prevent medical errors: A matter for american public policy. Policy Studies. 2008; 29(2): 137-143. http://dx.doi.org/10.1080/01442870802033381

[20] Pollack C, Bayley C, Mendiola M, McPhee S. Helping clinicians find resolution after a medical error. Camb Q Healthc Ethics. 2003; 12(2): 203-207. PMid: 12764888. http://dx.doi.org/10.1017/S0963180103002135

[21] Reason J. Human error: Models and management. BMJ. 2000; 320(7237): 768-770. PMid: 10720363. http://dx.doi.org/10.1136/bmj.320.7237.768

[22] Gregory B, Kaprielian VS. Anatomy of an error [Internet]. 2005 [cited 2012 Mar 21]. Available from: http://patientsafetyed.duhs.duke.edu/module_e/basic_tenets.html

[23] Sullivan M. Ethical principles in pain management. Pain Med. 2001; 2(2): 106-111. PMid: 15102298. http://dx.doi.org/10.1046/j.1526-4637.2001.002002106.x

[24] Gelling L. Ethical principles in healthcare research. Nurs Stand. 1999; 13(36): 39-42. PMid: 10497544. http://dx.doi.org/10.7748/ns1999.05.13.36.39.c2607

[25] Beauchamp TL, Childress JF. Respect for autonomy. In Principles of biomedical ethics (5th ed., pp. 57-336). New York: Oxford University Press; 2001.

[26] Kalra J, Massey K, Mulla A. Disclosure of medical error: Policies and practice. J R Soc Med. 2005; 98(7): 307-309. PMid: 15994590. http://dx.doi.org/10.1258/jrsm.98.7.307

[27] Kaidjian LC, Jones EW, Wu BJ, Forman-Hoffman V, Levi BH, Rosenthal GE. Disclosing medical errors to patients: Attitudes and practices of physicians and trainees. J Gen Intern Med. 2007; 22(7): 988-996. http://dx.doi.org/10.1007/si 1606-007-0227-z

[28] Robbennolt JK. Apologies and medical error. Clin Orthop Relat Res. 2009; 467(2): 376-382. http://dx.doi.org/10.1007/s11999-008-0580-1 
[29] Levinson W, Gallagher TH. Disclosing medical errors to patients: A status report in 2007. CMAJ. 2007; 177(3): 265-267. PMid: 17664451. http://dx.doi.org/10.1503/cmaj.061413

[30] Chafe R, Levinson W, Sullivan T. Disclosing errors that affect multiple patients. CMAJ. 2009; 180(11): 1125-1127. PMid: 19468121. http://dx.doi.org/10.1503/cmaj.081016

[31] Zientek DM. Medical error, malpractice and complications: A moral geography. HEC Forum. 2010; 22(2): $145-157$. http://dx.doi.org/10.1007/s10730-010-9130-9

[32] Wheat K. Applying ethical principles in healthcare practice. Br J Nurs. 2009; 18(17): 1062-1063. PMid: 19798006.

[33] MacDonald N, Attaran A. Medical errors, apologies and apology laws. CMAJ. 2009; 180(1): 11. PMid: 19124780. http://dx.doi.org/10.1503/cmaj.081997

[34] Jamal A, McKenzie K, Clark M. The impact of health information technology on the quality of medical and health care: A systematic review. HIM J. 2009; 38(3): 26-37. PMid: 19875852.

[35] Linz AJ, Fallon Jr. LF. Public perceptions regarding the impact of electronic medical records on health care quality and medical errors. J Controversial Med Claims. 2008; 15(2): 10-15.

[36] Pezzo MV, Pezzo SP. Physician evaluation after medical errors: Does having a computer decision aid help or hurt in hindsight? Med Decis Making. 2006; 26(1): 48-56. http://dx.doi.org/10.1177/0272989X05282644

[37] Paxton JH, Rubinfeld IS. Medical errors education: A prospective study of a new educational tool. Am J Med Qual. 2010; 25(2): 135-142. http://dx.doi.org/10.1177/1062860609353345 